\title{
Críticas à Resolução CNE/CES No9/2004 e Sugestões para o Novo Marco Regulatório do Ensino Jurídico Brasileiro
}

\author{
Eduardo Tomasevicius Filho' \\ Recebido em: 14/11/2014. Aprovado em: 01/12/2014. Disponibilizado em: 26/12/2014
}

1. Eduardo Tomasevicius Filho é Professor da Faculdade de Direito da USP e das Faculdades Integradas "Campos Salles".

Bacharel em Direito pela USP; Mestre em História Social pela USP; Doutor em Direito Civil pela USP. tomasevicius@usp.br.

\section{Resumo}

O objetivo desse texto é o de apresentar considerações acerca das diretrizes curriculares dos cursos de direito no Brasil. Fez-se breve retrospectiva sobre os mesmos, analisaram-se os dados colhidos no ENADE 2012 e apontaram-se as distorções decorrentes da regulação do ensino jurídico no Brasil. À guisa de conclusão, apresentaram-se sugestões para o futuro marco regulatório do ensino jurídico brasileiro. As sugestões contidas nesse texto, exclusivamente de cunho pessoal do autor e não traduzem a opinião de qualquer instituição, foram externalizadas oralmente na audiência pública realizada pela OAB/SP em julho de 2013 e na reunião aberta realizada pelo MEC na Faculdade de Direito da USP em outubro de 2013.

Palavras-chave: ensino jurídico, ensino superior, cursos jurídicos.

\begin{abstract}
The aim of this paper is to present considerations about the curriculum guidelines of legal education in Brazil. A short retrospective was presented, data collected in 2012 by ENADE was analyzed and the distortions arising from the regulation of legal education in Brazil were pointed up. As a conclusion, suggestions were presented for the prospective curriculum guidelines of the Brazilian legal education. The suggestions contained in this paper, which consist in the entire opinion of the author and do not reflect the opinion of any institution, were the core of his speeches at the public hearing beld by the OAB/SP in July 2013 and in the MEC meeting held at the USP Law School in October 2013.
\end{abstract}

Keywords: law education, undergraduation courses, law schools 
1. Breve retrospectiva sobre os cursos jurídicos no Brasil

$\mathrm{O}$ ensino jurídico confunde-se praticamente com a história do ensino superior no Brasil. Foram os cursos jurídicos aqueles verdadeiramente pensados pelos dirigentes da nação brasileira no inicio do Império. Cogitou-se àquela época a fundação de universidades. No entanto, por diversas razões, criaram-se apenas duas escolas de direito, em Olinda e em São Paulo, pela lei de 11 de agosto de $1827 .{ }^{1}$ Esses cursos não se destinavam propriamente à formação de advogados, juizes ou promotores, mas, sobretudo, à formação de quadros para as denominadas carreiras de Estado, tanto para atuação no Poder Judiciário, como também nos Poderes Executivo e Legislativo, como bem demonstram Alberto Venâncio Filho ${ }^{2} \mathrm{e}$ Sérgio Adorno. ${ }^{3}$ Tal fato não se comprova apenas por pesquisa biográfica sobre os dirigentes brasileiros, mas pelo currículo daquelas faculdades de direito.

Naquela época já se discutia a qualidade dos cursos jurídicos no Brasil. Reformas legislativas sobre o ensino foram feitas. Culparam-se as aulas expositivas pela baixa qualidade do ensino jurídico. Em 1879, Leôncio de Carvalho implantou a frequência livre. ${ }^{4}$ Em 1885, ampliou-se a duração dos

\footnotetext{
${ }^{1}$ BRASIL (Império). Lei de 11 de agosto de 1827. Crea dous cursos de sciencias jurídicas e sociaes, um na cidade de $\mathrm{S}$. Paulo e outro na de Olinda.

2 VENANCIO FILO. Alberto. Das Arcadas ao Bacharelismo; 2a ed. São Paulo: 2011 BRASIL (Império). Decreto $n^{\circ}$. 7.247, de 19 de abril de 1879. Reforma o ensino primário e secundário no município da Corte e o superior em todo o Império. ${ }^{3}$ ADORNO, Sergio. Os aprendizes do poder: o bacharelismo liberal na política brasileira. Rio de Janeiro: Paz e Terra, 1988

${ }^{4}$ BRASIL (Império). Decreto $n^{\circ}$. 7.247, de 19 de abril de 1879. Reforma o ensino primário e secundário no município da Corte e o superior em todo o Império.
}

TOMASEVICIUS FILHO, E.: Críticas À Resolução CNE/CES No9/2004 e Sugestões para o Novo cursos de cinco para seis anos, ${ }^{5}$ embora se tenha voltado ao regime de cinco anos logo em seguida. ${ }^{6}$ Em 1895, pela lavra de Benjamin Constant, inseriram-se disciplinas de Economia Política, Ciência da Administração, Ciência das Finanças e Contabilidade do Estado. ${ }^{7}$ Spencer Vampré, no início do século XX, implantou o método do caso ("case method"), bastante conhecido nos cursos de administração de empresas. Depois se voltou atrás em tudo o que foi feito.

Os alunos, em sua grande maioria, eram membros da elite brasileira ou nela ingressavam por meio da formação jurídica obtida nos cursos jurídicos. Os interesses envolvidos na regulação das faculdades voltavam-se ao atendimento das necessidades desse grupo. Com o aumento do número de pessoas pertencentes a essa elite brasileira, fez-se necessária a primeira ampliação das escolas de direito no Brasil no fim do século XIX e inicio do século XX, o que deu origem a faculdades na Bahia, Ceará, Rio de Janeiro, Paraná e Minas Gerais.

Na década de 1950, San Tiago Dantas continuava a apontar a falência do ensino jurídico. ${ }^{8}$ Todavia, mudanças efetivas - não necessariamente em termos de qualidade ocorreram no fim da década de 1960, para atender aos anseios da classe média brasileira,

\footnotetext{
${ }^{5}$ BRASIL (Império). Decreto $n^{\circ} .9 .360$, de 17 de janeiro de 1885. Dá novos estatutos às Faculdades de Direito.

${ }^{6}$ BRASIL (Império). Decreto $n^{\circ} .9 .522$, de 28 de novembro de 1885 . Suspende a execução dos estatutos das Faculdades de Direito mandados observar pelo Decreto $n^{\circ} .9 .360$, de 17 de janeiro do corrente anno.

${ }^{7}$ BRASIL. Lei $n^{\circ}$. 314, de 1895 . Reorganiza o ensino nas faculdades de direito.

${ }^{8}$ SAN TIAGO DANTAS, Francisco Clementino de. "A educação jurídica e a crise brasileira - aula inaugural dos cursos da Faculdade Nacional de Direito em 1955". Revista Forense. Rio de Janeiro. v. 159. p. 453. 1955
} 
a qual era do ensino superior por falta de vagas nas tradicionais faculdades do país. A reforma universitária de $1968^{\circ}$ permitiu a expansão do número de escolas de direito, que seriam mantidas pela iniciativa privada. Porém, isso não representou verdadeira democratização do ensino, pois ainda era reduzido o número de ingressantes no ensino superior. Devido ao surgimento de outros cursos superiores voltados à formação de pessoas aptas à administração, os cursos jurídicos passaram a enfatizar a formação de pessoas para atuação na atividade judiciária, como juizes, promotores, advogados procuradores e delegados de polícia, que, no Brasil, exercem funções de polícia judiciária. ${ }^{10}$

$\mathrm{Na}$ década de 1990, já no esteio da Constituição Federal de 1988, a qual cuidou da educação nos arts. 205 e seguintes, promulgou-se a Portaria MEC n ${ }^{\circ} 1.886$, de $1994,{ }^{11}$ a qual trouxe, em linhas gerais, a configuração atual dos cursos jurídicos no Brasil, ao estabelecer não apenas as disciplinas exigíveis, mas também a obrigatoriedade de realização de atividades complementares, monografia de fim de curso e estágio curricular obrigatório, com o oferecimento de núcleos de prática jurídica dentro das próprias instituições de ensino. Por fim, com a criação dos SINAES em 2003, por meio da Lei $\mathrm{n}^{\circ}$. 10.861, de 14 de abril de 2004, as diretrizes curriculares do curso de direito foram incrementadas por meio da Resolução CNE/CES n. 9, de 2004, com a definição das competências e habilidades esperadas dos egressos e exigência de elaboração de projeto pedagógico de curso, além das avaliações constantes para fins de

\footnotetext{
${ }^{9}$ BRASIL. Lei $n^{\circ} .5 .540$, de 28 de novembro de 1968. Fixa normas de organização e funcionamento do ensino superior e sua articulação com a escola média, e dá outras providências.

${ }^{10}$ BRASIL. Resolução CFE $n^{\circ}$. 3, de 25 de fevereiro de 1972.
}

reconhecimento e de renovação do reconhecimento dos cursos. ${ }^{12}$

\section{As deficiências da atual regulação do ensino jurídico}

Ao contrário do que se possa imaginar, o ensino jurídico brasileiro não está em crise. O que está em crise é o marco regulatório do ensino jurídico, atualmente consubstanciado na Resolução CNE/CES n. 9/2004, a qual ainda reflete o paradigma elitista dos séculos XIX e XX em matéria de ensino jurídico, por partirem dos seguintes pressupostos: 1) todo ingressante em curso jurídico pretende exercer as carreiras tradicionais, como as de advogado, juiz, promotor e delegado de polícia; 2) todos os alunos têm a mesma faixa etária e são egressos de escolas de qualidade semelhante; 3) todos os alunos estudam de dia e não exercem atividade remunerada (porque são supostamente sustentados pelos pais ou responsável); 4) os alunos tiveram oportunidades ou histórias de vida similares; 5) o Brasil é um país sem desigualdades regionais e que todas as regiões têm as mesmas necessidades e buscam os mesmos interesses.

Com efeito, somente na última década houve verdadeira democratização do ensino superior no Brasil, por meio de sua expansão em número de cursos, vagas e instituições de ensino, assim como pelas ações afirmativas e concessão de bolsas de estudos, como as do PROUNI, que representam verdadeiro avanço em termos de política social. Consequentemente, ocorreu a ampliação e diversificação dos interesses dos ingressantes

\footnotetext{
${ }^{11}$ BRASIL. Portaria MEC $n^{\circ} .1 .886$, de 30 de dezembro de 1994. Fixa as diretrizes curriculares e o conteúdo mínimo do curso jurídico.

12 BRASIL. Resolução CNE/CES n. 9, 29 de setembro de 2004. Institui as diretrizes curriculares nacionais do curso de graduação em direito e dá outras providências.
} 
do ensino superior, não apenas nos cursos jurídicos, mas nos cursos superiores em geral. Por exemplo, há alunos com 18 a 25 anos de idade, sustentados pelos pais, mas a maior parte dos alunos tem entre 25 e 60 anos de idade e trabalha de dia para pagar a faculdade cursada à noite, com o sonho de exercer qualquer das carreiras jurídicas. Há alunos desta mesma faixa etária, buscando uma segunda formação em nível superior a título de complementação profissional. Tem aqueles que cursam direito sem qualquer pretensão de exercício de qualquer carreira jurídica e só o fazem para não serem dispensados de seus empregos atuais. Há muita gente que quer estudar direito só para conhecer seus direitos, para ser melhor empresário, ou para ser um bom líder comunitário. Inclusive, há quem ainda conserva aquele antigo sonho de que a conclusão do curso de direito lhe atribuirá dignidade, para serem reconhecidos como "doutores" pela família e amigos, isso sem falar naqueles que veem na freqüência à faculdade apenas um mero espaço de socialização.

Somados a esses fatos, existem, em todos os cursos superiores brasileiros, alunos que estudaram em boas escolas particulares no ensino médio, assim corno há grande quantidade de alunos que, infelizmente, estudaram escolas públicas ruins. Tem aqueles que participaram do programa de Educação de Jovens e Adultos - EJA - como há aqueles que concluíram o ensino médio muito tempo atrás e só recentemente conseguiram ingressar no ensino superior. Com isso, existem alunos com sólida formação, como há alunos com precária formação e outros que buscam a alfabetização. Ademais, existem alunos com vocação para a pesquisa e existem alunos que apenas buscam profissionalização, a qual poderia ser obtida no próprio ensino médio em outras carreiras. Do mesmo modo, existem universidades com grandes bibliotecas, professores altamente titulados com vasta produção científica, assim como há universidades com bibliotecas com exemplares suficientes para atendimento à demanda dos alunos para as provas, com professores inseridos no mercado de trabalho e que não se interessam pela carreira exclusivamente acadêmica por opção pessoal.

Em vista desse quadro atual, nota-se que o modelo regulatório precisa ser ajustado. Regulação, como se sabe, consiste na forte atuação do Estado no direcionamento da atividade econômica. Está situada entre o exercício do poder de polícia e a realização da atividade pelo próprio Estado. ${ }^{13}$ Em termos estruturais, baseia-se na teoria dos sistemas, ${ }^{14}$ que prevê mecanismos de entradas de informações ("inputs") fornecidos pelo órgão regulador, respostas por mecanismo de saída ("output") e canais de retroalimentação do sistema, a partir de informações colhidas da realidade a ser regulada.

Como já afirmado, o problema dos cursos jurídicos não está nos cursos em si mesmos, mas no marco regulatório do sistema. O sistema atual, por ainda refletir o paradigma anterior à década de 1990, tem "inputs" muito restritos, que não fazem mais a correta leitura dos dados, provocando respostas inadequadas. A insistência no uso de "inputs" inadequados só levará mesmo à perda de estabilidade do sistema como um todo, por excesso de regulações e de correções de rotas supostamente equivocadas. Para sustentar essa afirmação, serão usados os dados fornecidos pelo INEP, referentes ao resultado do ENADE 2012.
${ }^{13}$ SALOMÃO FILHO, Calixto. Regulação da Atividade Econômica; 2a ed. São Paulo: Malheiros, 2008
${ }^{14}$ ASHBY, W. Ross. Introdução à cibernética; trad. Gita K. Guinsburg; ver. Geraldo Gerson de Souza. São Paulo: Perspectiva, 1970 
Quantidade de IES participantes do ENADE 2012

\begin{tabular}{|l|c|c|c|c|c|}
\hline & N & NE & CO & SE & S \\
\hline Universidades Públicas & 13 & 34 & 14 & 16 & 24 \\
\hline Universidades Privadas & 3 & 13 & 9 & 103 & 79 \\
\hline Centros Universitários Públicos & 1 & - & - & - & 1 \\
\hline Centros Universitários Privados & 6 & 6 & 13 & 63 & 17 \\
\hline Faculdades Públicas & 1 & 2 & 2 & 8 & - \\
\hline Faculdades Privadas & 37 & 129 & 64 & 208 & 84 \\
\hline
\end{tabular}

Fonte: INEP15

Quantidade de alunos concluintes em 2012

\begin{tabular}{|l|c|c|c|c|c|}
\hline & N & NE & CO & SE & S \\
\hline Universidades Públicas & 840 & 3279 & 1263 & 3017 & 2593 \\
\hline Universidades Privadas & 765 & 5700 & 4926 & 21176 & 10177 \\
\hline Centros Universitários Públicos & 252 & - & - & - & 75 \\
\hline Centros Universitários Privados & 1184 & 2279 & 4835 & 9756 & 2479 \\
\hline Faculdades Públicas & 191 & 210 & 153 & 1415 & - \\
\hline Faculdades Privadas & 4550 & 14112 & 5555 & 15532 & 6248 \\
\hline
\end{tabular}

Fonte: INEP16

Distribuição das notas do ENADE 2012

\begin{tabular}{|l|c|c|c|c|c|}
\hline & $\mathbf{1}$ & $\mathbf{2}$ & $\mathbf{3}$ & $\mathbf{4}$ & $\mathbf{5}$ \\
\hline Universidades Públicas & 2 & 2 & 24 & 31 & 32 \\
\hline Universidades Privadas & 4 & 4 & 110 & 40 & 5 \\
\hline Centros Universitários Públicos & - & - & - & - & - \\
\hline Centros Universitários Privados & 3 & 3 & 50 & 19 & - \\
\hline
\end{tabular}

15 BRASIL. INEP. Conceito ENADE - 2012.

Disponível em: http://download.inep.gov.br/educacao_superior/enade/planilhas/2012/conceito_enade_2012.xlsx Acessado em: 01/fev/2014

16 Idem. Ibidem. 


\begin{tabular}{|l|c|c|c|c|c|}
\hline Faculdades Públicas & - & - & 3 & 1 & - \\
\hline Faculdades Privadas & 20 & 20 & 244 & 70 & 6 \\
\hline
\end{tabular}

Fonte: INEP ${ }^{17}$

Distribuição das Notas das IES no ENADE 2012 - por região

\begin{tabular}{|l|c|c|c|c|c|}
\hline & $\mathbf{1}$ & $\mathbf{2}$ & $\mathbf{3}$ & $\mathbf{4}$ & $\mathbf{5}$ \\
\hline Norte & 2 & 15 & 27 & 7 & 2 \\
\hline Nordeste & 9 & 63 & 74 & 24 & 11 \\
\hline Centro-Oeste & 3 & 42 & 41 & 8 & 8 \\
\hline Sudeste & 9 & 109 & 179 & 95 & 12 \\
\hline Sul & 6 & 47 & 108 & 33 & 10 \\
\hline
\end{tabular}

Fonte: INEP18

Quantidade de alunos - Nota x IES

\begin{tabular}{|l|c|c|c|c|c|}
\hline & $\mathbf{1}$ & $\mathbf{2}$ & $\mathbf{3}$ & $\mathbf{4}$ & $\mathbf{5}$ \\
\hline Universidades Públicas & 199 & 1206 & 2891 & 3681 & 2684 \\
\hline Universidades Privadas & 280 & 12396 & 25207 & 4687 & 133 \\
\hline Centros Universitários Públicos & - & 327 & - & - & - \\
\hline Centros Universitários Privados & 165 & 8944 & 9171 & 2081 & - \\
\hline Faculdades Públicas & 70 & 624 & 987 & 279 & - \\
\hline Faculdades Privadas & 1885 & 16320 & 21950 & 5077 & 352 \\
\hline Total & $\mathbf{2 5 9 9}$ & $\mathbf{3 9 7 2 7}$ & $\mathbf{6 0 2 0 6}$ & $\mathbf{1 5 8 0 5}$ & $\mathbf{3 3 4 9}$ \\
\hline
\end{tabular}

Fonte: INEP19

17 Idem. Ibidem.

18 Idem. Ibidem.

19 Idem. Ibidem. 
Observa-se que a maior quantidade de instituições de ensino superior é composta por faculdades privadas, seguidas pelas universidades privadas e centros universitários privados. Em termos de alunos, as universidades privadas são as que mais recebem alunos, seguidas pelas faculdades privadas e centros universitários privados. Quanto aos resultados, constata-se que a maior parte das instituições obteve a nota 3 . A segunda nota foi 4 . Em se tratando de quantidade de alunos, a maior parte dos estudantes brasileiros obteve a nota 3 , seguida pela nota 2 .

Quando não havia vagas para todos os interessados em ingressar em cursos jurídicos, necessariamente havia seleção dos alunos preparados por meio dos exames vestibulares. A baixa qualidade do ensino médio em geral não era levada em consideração, porque os vestibulares barravam os alunos sem formação adequada nesse nível. Portanto, os resultados obtidos por alunos selecionados ao final de cinco anos eram bons ou satisfatórios. Agora, os cursos oferecidos por universidades públicas ainda continuam atraindo os melhores alunos pela gratuidade do ensino, o que leva à obtenção de bons resultados, enquanto os alunos que não tiveram a oportunidade de cursar boas escolas de ensino médio, são absorvidos pelas instituições privadas. Assim, alunos de formação básica distinta terão resultados distintos quando submetidos aos mesmos exames

(ENADE e Exame de Ordem), os quais pouco refletem a qualidade dos cursos jurídicos. Ao contrário, refletem, com maior probabilidade, as deficiências do ensino médio no Brasil.

Alunos que tiveram a oportunidade de cursar boas escolas de ensino médio no Brasil são, em geral, oriundos de famílias de renda elevada, pois, do contrário, não seria possível pagar as elevadas mensalidades escolares.
Esses alunos, em sua grande maioria, não precisam trabalhar para sustentarem-se durante os cinco anos de curso. Por outro lado, alunos que não tiveram a mesma oportunidade, necessitam, em sua maioria, trabalhar de dia para pagar o curso frequentado à noite. Chegam cansados à aula e têm menos tempo disponível para estudar. Assim, alunos que não tiveram o mesmo tempo de estudo terão resultados distintos, quando submetidos ao mesmo exame. Esses resultados, portanto, refletem, na verdade, as desigualdades sociais do Brasil.

A avaliação feita apenas por aqueles que pretendem exercer carreiras jurídicas pode ser indicador do aprendizado do aluno. Porém, se alunos que tiveram oportunidade de dedicação ao curso forem avaliados no mesmo pela mesma prova, ao lado de alunos que trabalhavam de dia e cursavam à noite, bem como com alunos desinteressados no exercício de qualquer profissão jurídica, somados aos alunos que só buscavam a "dignidade de doutor", inevitavelmente os resultados serão diferentes. Ante essa realidade complexa, não se pode exigir do corpo discente jurídico brasileiro que os índices de aprovação nos Exames da OAB sejam elevados. Mais uma vez, esses resultados pouco refletem a qualidade dos cursos jurídicos, mas refletem, com maior probabilidade, os diversos interesses dos alunos no Brasil.

\section{As distorções provocadas pela regulação inadequada}

Pela aplicação do principio da igualdade, a regulação do ensino exige que o aluno de Roraima tenha o mesmo ensino jurídico ministrado ao aluno do Rio Grande do Sul ou que seja indiferente estudar no Largo de São Francisco ou em uma faculdade isolada em São Paulo. Em última análise, deveria ser indiferente estudar aqui ou acolá. É materialmente impossível que, em um país do 
tamanho do Brasil, que apresenta fortes desigualdades regionais, inclusive dentro da mesma cidade, como é o caso de São Paulo, que todas as instituições de ensino sejam igualmente boas. Basta ver o The World University Rankings na área de ciências: das 100 universidades "top", os EUA têm 46 universidades; o Reino Unido tem 16 universidades; a Holanda tem 8 universidades; a Austrália tem 7 universidades; o Canadá tem 4 universidades; Alemanha e Hong Kong tem 3 universidades cada; Bélgica, China e França têm 2 universidades cada; África do Sul, Coréia do Sul, Espanha, Japão Nova Zelândia, Singapura e Suíça têm 1 universidade cada. Embora esse ranking seja discutível, trata-se de parâmetro suficiente para lançar a pergunta: como a regulação do ensino jurídico no Brasil pode pretender que o país tenha mil escolas "top", se nenhum outro país do mundo consegue tal façanha? Se é difícil ter uma universidade de ponta, que dirá ter mil universidades de ponta espalhadas por todo o Brasil por força do princípio da igualdade, exigindo-se que todas tenham somente professores com doutorado, dedicação exclusiva à decência e vasta publicação? Logo, a resposta da regulação do ensino jurídico, provocada pelos supostos maus resultados, acaba sendo equivocada. Por exemplo, alunos de universidades públicas, que deveriam ser os mais cobrados em razão da atração dos alunos mais bem preparados, pelo privilégio do ensino gratuito e da concentração de professores com elevada titulação acadêmica, sofrem cobranças brandas por terem obtido bons resultados nesses exames. Já os alunos que não tiveram a mesma oportunidade de aprendizagem no ensino médio, nem a mesma disponibilidade de tempo para estudos, ficam estigmatizados pelo resultado global da instituição de ensino que cursaram.

A jornada de trabalho dos professores não altera o rendimento dos alunos dos cursos jurídicos, pois não se pode inferir que mais tempo dentro da instituição signifique maior tempo de pesquisa ou de competências e habilidades de ensino. Vale lembrar que, se a maior parte dos alunos trabalha de dia e estuda à noite, a presença do professor durante o dia na instituição não resultará no aprimoramento da relação professor-aluno.

Em termos de mercado de trabalho, caso os índices de aprovação no Exame de Ordem fossem elevados no Brasil, a oferta de profissionais seria, no mínimo, duplicada imediatamente, o que provocaria a completa desorganização do setor. É da essência do funcionamento de um órgão de classe que o número de aprovados no Exame de Ordem seja baixo, pois esse índice é aquele necessário para obter o ponto de equilíbrio entre a oferta e a procura por serviços jurídicos. Logo, não é possível contar com a "mão invisível" do mercado para regular a oferta e a procura.

Quando os resultados do ENADE ou de Exames de Ordem são divulgados, propõe-se a punição das instituições ou o seu fechamento, porque o sistema regulatório atual pressupõe que o aluno seja incapaz de avaliar se o curso é bom ou ruim e que só descobrirá ter sido enganado quando participa do ENADE ou presta o Exame de Ordem. Porém, é irreal imaginar que aluno de curso jurídico, por menor que seja a sua percepção da realidade, não seja capaz de descobrir se este é bom ou ruim, após ter permanecido por cinco anos, durante cinco dias da semana, convivendo com, no mínimo, cinquenta pessoas dentro de uma sala de aula. No afã de proteger os incautos alunos, provoca-se efeito contrário: a excessiva regulação, por sua inflexibilidade e excessivo rigor, tem levado à concentração do mercado e, nesse cenário, esses mesmos alunos ficarão sim mais vulneráveis a abusos do poder econômico, além de penalizar aquelas instituições cujo corpo discente não tem muitos alunos interessados em atuar nas tradicionais profissões jurídicas, mas, o de 
apenas manter sua empregabilidade ou de buscar suprir suas deficiências de aprendizado dos ensinos médio e fundamental.

\section{4. À guisa de conclusão: sugestões para o novo marco regulatório do ensino jurídico}

Em 2013, a Ordem dos Advogados do Brasil realizou audiências públicas em suas seccionais para a discussão do quadro atual do ensino jurídico e para a coleta de sugestões para encaminhamento das mesmas para o Ministério da Educação, quando da elaboração das novas diretrizes curriculares dos cursos de direito. $\mathrm{Na}$ seccional paulista, esta realizou-se em julho de 2013. O Ministério da Educação, por sua vez, realizou audiência pública na Faculdade de Direito da USP em outubro de 2013 com a mesma finalidade. Abaixo seguem sugestões para o novo marco regulatório do ensino jurídico, as quais foram apresentadas pelo autor desse texto nessas ocasiões.

A regulação do ensino jurídico não pode basear-se nos pressupostos de que todo ingressante em curso de direito tenha tido a mesma formação no ensino médio; que não exerça atividade remunerada durante o curso; e que pretenda, ao final do curso, inexoravelmente pretenda ingressar no mercado de trabalho por meio do exercício de qualquer das profissões jurídicas. Ao contrário, os "inputs" devem ser "democratizados", para que se contemplem os diversos interesses dos alunos e da sociedade. Sustenta-se que sobre o problema do ensino jurídico está na incompreensão ou não-desenvolvimento da ciência do direito, assim como com a necessidade de conhecimento de outros idiomas. Tais fatos são problemas secundários, porque exigem a solução de problema prévio: a crise do ensino médio.
A respeito desse fato, não se trata apenas da deficiência do ensino, mas sim quanto às discussões travadas entre os especialistas da Faculdade de Educação e do próprio MEC sobre o que fazer com esse nível de ensino. Quem está de fora, pressupõe a existência de diálogo entre as câmaras do ensino médio e do superior. Como contribuição para o fortalecimento do ensino médio, os responsáveis pela regulação do ensino jurídico deveriam compartilhar seus pontos de vista com os responsáveis do MEC pelo ensino médio, com o intuito de buscar soluções conjuntas para o ensino superior e vice-versa. Também seria interessante perquirir por que tanta gente quer cursar direito, ainda que não venha a exercer qualquer profissão jurídica: continuar na mesma profissão ou ir para profissão distinta.

Com a democratização do ensino superior e a diversidade de interesses, os cursos jurídicos não podem mais servir apenas para a formação para profissões estritamente jurídicas, como as de advogado, juiz, promotor, delegado, etc. Deveriam também se voltar à formação de melhores cidadãos ou especialistas em convivência humana. Isso renovaria - ou oxigenaria - a formação do bacharel em direito e abriria novas perspectivas de trabalho. Como já dito, se há 700 mil inscritos na OAB no Brasil e há 700 mil estudantes, o mercado de trabalho de advogados entraria em colapso, porque o Brasil teria 1,5 milhão de advogados em cinco anos!

Poder-se-iam criar regras mais claras para cursos diurnos e para cursos noturnos, pois há a ficção de que curso noturno é igual a curso diurno. Mas, como dito acima, essa não é a realidade. Alunos do noturno estão cansados, isso sem falar nos problemas de mobilidade urbana te da violência das grandes cidades. Os cursos devem ter a mesma qualidade, mas, em contrapartida, as diretrizes curriculares nacionais deveriam 
ordenar a implantação de novos mecanismos de compensação dessas deficiências.

A própria duração dos cursos jurídicos poderia ser revista. Na década de 1970, exigiam-se 2700 horas; em 2004, ampliou-se para 3300 horas e, atualmente, está em 3700 horas. A justificativa para tamanho aumento estaria no fato de que as disciplinas tiveram ampliação de seus conteúdos. Inclusive há sugestões de que se amplie a duração dos cursos para sete anos. No entanto, a própria velocidade de mutação do conhecimento impõe o reconhecimento de que a graduação em direito é apenas o primeiro passo para o aprendizado, porque, ao longo da carreira profissional, esse conhecimento necessariamente será substituído pelo estudo individual ou em cursos de pós-graduação. Seria muito mais útil ensinar aos alunos a reciclarem-se, em vez de adotar o posicionamento de que a graduação será a única oportunidade de aquisição do conhecimento. Nesse sentido, a duração dos cursos jurídicos poderia ser reduzida para quatro anos, porque, nesse período, o aluno já tem conhecimentos suficientes para o exercício das profissões jurídicas. Vale lembrar que o quinto ano dos cursos jurídicos acaba sendo um período de mera revisão de conteúdos estudados nos anos anteriores ou a especialização em matérias de pouco interesse para os alunos em geral.

Seria preciso levar em conta que as diretrizes curriculares dos cursos jurídicos exigem atividades no período diurno, quando boa parte dos alunos do Brasil trabalha o dia todo para pagar a mensalidade do curso noturno. Esse é um dos motivos da aversão dos alunos pelos Núcleos de Prática Jurídica, porque participar dos mesmos gera risco de dispensa do emprego, colocando em risco seu sustento pessoal e das suas famílias. Estes escritórios devem ser obrigatoriamente oferecidos pelas instituições de ensino superior, mas a participação nos mesmos deveria ser facultativa. Há faculdades de direito instaladas em municípios em que não há oportunidades de estágio. Nesse caso, os Núcleos de Prática Jurídica são a única forma de aquisição de experiências profissionais quando do ingresso no mercado de trabalho. Já em cidades como São Paulo, em que há muitas oportunidades de estágio, a sua realização obrigatória dentro do ambiente escolar é prejudicial ao próprio aluno, porque este já tem como ser absorvido pelo mercado de trabalho antes mesmo da conclusão do curso. Seria salutar a proibição expressa de estágios até $\mathrm{o} 4^{\circ}$ semestre, mas a imposição de residência, tal qual a da área médica, somente contribuiria para a completa elitização dos cursos jurídicos, aos moldes da elitização já existente nos cursos de medicina no Brasil.

Quanto às monografias de final de curso, é ilusório acreditar que os $700 \mathrm{mil}$ elaborados no Brasil sejam de qualidade. Haja criatividade e competência! É evidente que a grande maioria dos trabalhos não é de boa qualidade - afinal, os alunos estão acostumados a responder provas e não, a fazer trabalhos finais em cada disciplina cursada. É preciso considerar que apenas parte dos alunos tem vocação para a pesquisa individual em bibliotecas. Assim, dever-se-ia dar duas opções aos alunos: aqueles com vocação para a pesquisa deveriam fazer uma monografia nos moldes atuais e os demais alunos, que não têm tanta vocação para a pesquisa, mas que são bons comunicadores, com habilidades interpessoais, deveriam executar um projeto de extensão universitária na área da cidadania. Trabalhos dessa natureza também exigem análise da realidade social brasileira, pesquisa, coleta de dados, atuação em equipe e elaboração de texto sobre a execução do projeto. Esses projetos de extensão universitária seriam muito mais úteis à sociedade do que milhares de monografias inúteis, feitas apenas para a obtenção do diploma. Ademais, atender-se- 
iam as exigências de ensino, pesquisa e extensão exigidas das universidades.

Por fim, o ENADE. O período trienal é adequado para cursos que tenham quatro anos de duração, pois, em tese, consegue-se avaliar o aluno, quando ingressa e quando egressa do curso. Em cursos jurídicos, com cinco anos de duração, os resultados ficam distorcidos. Por isso, o prazo para a realização do ENADE deveria ser de dois anos, porque se poderia abranger com mais precisão o aluno ingressante e o aluno egresso em três oportunidades distintas. Eventual aplicação anual do ENADE seria equivocada, por representar excesso de regulação, já que, em matéria educacional, as mudanças são lentas e é preciso respeitar essa característica a fim de que se possa fazer nova medição dos resultados, sob pena de perder-se o controle do sistema.

\section{Bibliografia}

1. BRASIL (Império). Decreto $n^{\circ}$. 7.247, de 19 de abril de 1879. Reforma o ensino primário e secundário no município da Corte e o superior em todo o Império.

2. . Decreto $n^{\circ}$. 9.360, de 17 de janeiro de 1885. Dá novos estatutos às Faculdades de Direito.

3. Decreto $\mathrm{n}^{\circ}$. 9.522, de 28 de novembro de 1885. Suspende a execução dos estatutos das Faculdades de Direito mandados observar pelo Decreto n ${ }^{\circ}$ 9.360, de 17 de janeiro do corrente anno. 4. . Lei de 11 de agosto de 1827. Crea dous cursos de sciencias jurídicas e sociaes, um na cidade de S. Paulo e outro na de Olinda.

5. BRASIL. Lei $n^{\circ}$. 314, de 1895. Reorganiza o ensino nas faculdades de direito.

6. Lei $n^{\circ} .5 .540$, de 28 de novembro de 1968. Fixa normas de organização e funcionamento do ensino superior e sua articulação com a escola média, e dá outras providências.

7. Portaria MEC n. 1.886, de 30 de dezembro de 1994. Fixa as diretrizes curriculares e o conteúdo mínimo do curso jurídico.

8. Resolução CNE/CES n . 9, 29 de setembro de 2004. Institui as diretrizes curriculares nacionais do curso de graduação em direito e dá outras providências.

9. Resolução CFE nº. 3, de 25 de fevereiro de 1972.

10. BRASIL. INEP. Conceito ENADE 2012. Disponível em: http://download.inep.gov.br/educacao_sup erior/enade/planilhas/2012/conceito_enade _2012.xlsx. Acessado em: 01/fev/2014.

11. ADORNO, Sergio. Os aprendizes do poder: o bacharelismo liberal na política brasileira. Rio de Janeiro: Paz e Terra, 1988.

12. ASHBY, W. Ross. Introdução à cibernética; trad. Gita K. Guinsburg; ver. Geraldo Gerson de Souza. São Paulo: Perspectiva, 1970. 
13. SAN TIAGO DANTAS, Francisco Clementino de. "A educação jurídica e a crise brasileira - aula inaugural dos cursos da Faculdade Nacional de Direito em 1955". Revista Forense. Rio de Janeiro. v. 159. p. 453. 1955.

14. SALOMÃO FILHO, Calixto. Regulação da Atividade Econômica; $2^{\mathrm{a}}$ ed. São Paulo: Malheiros, 2008.
15. THE WORLD UNIVERSITY RANKINGS. Disponível em: http://www.Timeshigher education.co.uk/world-universityrankings/2013-14/worldranking.Acessadoem:2/fev/2014.

16. VENANCIO FILO. Alberto. Das Arcadas ao Bacharelismo; $2^{a}$ ed. São Paulo: 2011. 